\title{
Valsartan (or/and Nitrosamine) Induced BCC and Dysplastic Nevi: Current Insights
}

\author{
${ }^{*}$ Georgi Tchernev ${ }^{1}$, Nikhil Oliveira ${ }^{1}$, Lorraine Joseph Kandathil ${ }^{1}$, James W Patterson ${ }^{2}$ \\ ${ }^{1}$ Onkoderma- Policlinic for Dermatology, Venereology and Dermatologic Surgery, General Skobelev 26, 1606, Sofia, Bulgaria \\ ${ }^{2}$ Professor Emeritus of Pathology, University of Virginia, USA
}

Received: December 18, 2021; Accepted: December 23, 2021; Published: December 24, 2021

*Corresponding author: Georgi Tchernev, Onkoderma- Policlinic for Dermatology, Venereology and Dermatologic Surgery, General Skobelev 26, 1606, Sofia, Bulgaria, E-mail: georgi_tchernev@yahoo.de

\begin{abstract}
Introduction: Contamination of drugs for high blood pressure (sartans/ angiotensin receptor blockers) with nitrosamines occurs during the manufacturing process and has proven to be a serious international health problem. The reason for this problem is that the 4 nitrosamines discovered so far have been associated with the simultaneous or gradual development of cutaneous tumors as well as tumors of other organ systems. The presence of angiotensin receptors in melanocytic and keratinocytic tumors and their metastases adds difficulty when attempting to determine the relative importance of each of these two components (i.e. nitrosamines and angiotensin receptors) in the context of carcinogenesis.
\end{abstract}

Case report: We report a 40-year-old patient with arterial hypertension with a duration of skin complaints of about 7 months, clinically manifested by 1 ) the appearance of a solitary tumor near the medial corner of the left eye, verified histologically as Basal Cell Carcinoma (BCC), and 2) multiple, eruptive dysplastic nevi in the area of the posterior sweat gutter. The patient's systemic medications included: bisoprolol 5mg (1-0-1/2) and indapamide 1.5mg (1-00 ), taken for one year, and 2 years of treatment with amlodipine / valsartan - $5 \mathrm{mg} / 160 \mathrm{mg} \mathrm{(1-0-1/2)}$ for an initial period of 1 year, followed by a reduced dose of (1/2-0-0) for an additional year.

Conclusion: We report the simultaneous development of basal cell carcinoma and dysplastic nevi after the use of a preparation containing generic valsartan. We discuss 1) the role of nitrosamines as possible major factors in the development of dysplastic nevi and BCC; 2) the possible effect of sartans themselves on angiotensin receptors in the skin and: 3) a new, innovative scheme for treatment of drug-induced BCC by cryoimmunotherapy.

Keywords

Nitrosamines; Valsartan; Angiotensin Receptor Blockers; Arterial Hypertension; Melanoma; BCC; Cryoimmunotherapy

\section{Introduction}

Drug-mediated carcinogenesis is a complex process in which the development of single or multiple neoplasms is observed after initiation of a particular drug therapy [1]. The process of induction of a certain neoplastic cell branch can be driven by different mechanisms and proceeds through the stages of (1) initiation, (2) tumor promotion and (3) progression of a premalignant to a malignant lesion (2). Nitrosamines have long been known as important initiating factors in carcinogenesis [2]. The transition to the third phase mentioned above could be spontaneous or potentiated by mutagens or other initiating agents [2]. Whether the active component of the drug itself, or impurities in the form of nitrosamines, are to blame for this process remains a mystery $[1,3]$. The lack of follow-up evidence to clarify the troubling data shared in 2015/2016 regarding the use of sartans/ angiotensin receptor blockers and the risk of developing various skin tumors is at least concerning $[1,4,5]$. However, this evidence is probably multifactorial $[1,6,7]$. The introduction, monitoring and recording of so called "dose-dependent time intervals for generating a neoplastic cell clone" or "for the transformation of an existing normal one into a pathological/ tumor one" are steps in the right direction [7]. The reason is that they show a certain stereotypical clinical behaviour and recurrence of events and processes that can then be further analysed [7]. The stereotypical recurrence is indicative of existing dependencies or potentially causal relationships [7].

Another question is, what are the exact mechanisms leading to the end condition defined by us as a tumor [2]? Tumor development may be potentiated by: 1) the active ingredient of a particular drug (although unlikely) [8-10], in this case the sartan/ angiotensin receptor blocker (due to the established presence of angiotensin receptors in the skin [11]); and 2) contaminants in the form of nitrosamines (four so far, according to official data), causing up to 15 different tumors (very likely) [1,3]. Thus far, the dynamics of development of skin neoplasms (epithelial and melanocytic) show that they could be dose-dependent $[1,7]$ and that they can occur regardless of whether the agents are generics or original sartans [1,7]. This "stereotypical tumor behaviour" has been established in our clinical observations [1,7]. A further issue revolves around another possible unifying pathogenetic factor: the presence or absence of nitrosamines, as well as their quantitative identification $[1,7]$. In practice, the presence or absence of nitrosamines has been difficult to establish (being often institutionally and geographically determined) [1,3,6$9,12]$. Interestingly, this difficulty in itself has tended to promote additional focus on the potential role of nitrosamines as a key one in tumor development $[1,3,12]$. 


\section{Case Report}

We report the case of a 40 -year-old patient who presented in the dermatology clinic with medical complaints of about 6-7 months duration. He reported: 1) multiple pigmented lesions on the upper back, and 2) the parallel appearance of a solitary, slightly raised tumor-like lesion located in close proximity to the left medial canthus (figures 1a-c, 2a, 2b). An ambulatory biopsy of the latter showed a high-risk superficial basal cell carcinoma. There are no anamnestic data on painful sunburns in the past, and there is no information about the presence of skin cancer in relatives.

For about 2 years, the patient has carried a diagnosis of arterial hypertension. The patient's current medications include: bisoprolol 5mg (1-0-1 / 2) and indapamide 1.5mg (1-0-0), taken for one year, and 2 years of treatment with amlodipine / valsartan - $5 \mathrm{mg} / 160 \mathrm{mg}$ (1-0-1 / 2) for an initial period of 1 year, followed by a reduced dose of (1/2-0-0) for an additional year up to the time of the review.

At the time of his dermatological examination we found multiple acquired eruptive melanocytic nevi with minimal diameter on the upper back, some of which - clinically and dermatoscopically - met criteria for dysplastic nevi (figures 1a-1c). Surgical excision was performed on one melanocytic nevus (figures 1d, 1e, 1f), which subsequently revealed histological evidence of dysplastic nevus, with clear resection margins. Regarding the histologicallyidentified superficial basal cell carcinoma of the left canthal area, cryo-immunotherapy (cryo-spray) was planned and initiated due to the patient's refusal to undergo surgical treatment (figures 2a-2g): Lesions were treated using a CRY -AC container (Brymill Cryogenic Systems, Ellington, Connecticut) at a distance of 4 to 5 $\mathrm{cm}$ for a period of approximately 8 seconds for initially 4 cycles at day 1 , obtaining a 2-mm margin around the histopathologicallyestimated tumor lesion. Immediately after the spray session with liquid nitrogen (same day), the patient was instructed to apply a thin coat of imiquimod $5 \%$ cream for 5 consecutive nights, to take 2 days off, and repeat for a total of 6 weeks. During the first cryo-immuno-session, about the time of the 3rd application of imiquimod 5\% cream, we observed the development of local inflammation, followed by abundant secretion in the form of transudate, perilesional redness, and severe pain in the medial corner of the eye, due to which treatment was temporarily discontinued immediately after the fifth day (figures 2c, 2d). Systemic antibiotic treatment with clarithromycin $500 \mathrm{mg}$, once daily for 10 days, was started in combination with silver sulfadiazine cream 1\% twice daily (topical therapy) for 10 days (figures 2e, 2f). Subsequently, topical therapy was replaced by 3 times daily administration of a complex gel containing vitamin $\mathrm{E}$, provitamin B5 and medical silicones, for an additional period of 5 days (figures $2 \mathrm{f}, 2 \mathrm{~g}$ ). We observed significant regression of the lesion, beginning in the periphery, followed by complete healing and a good cosmetic result (figure $2 \mathrm{~g}$ ). The patient was informed of the need to follow regular monthly clinical check-ups for a minimum of one year in order to rule out local recurrence.
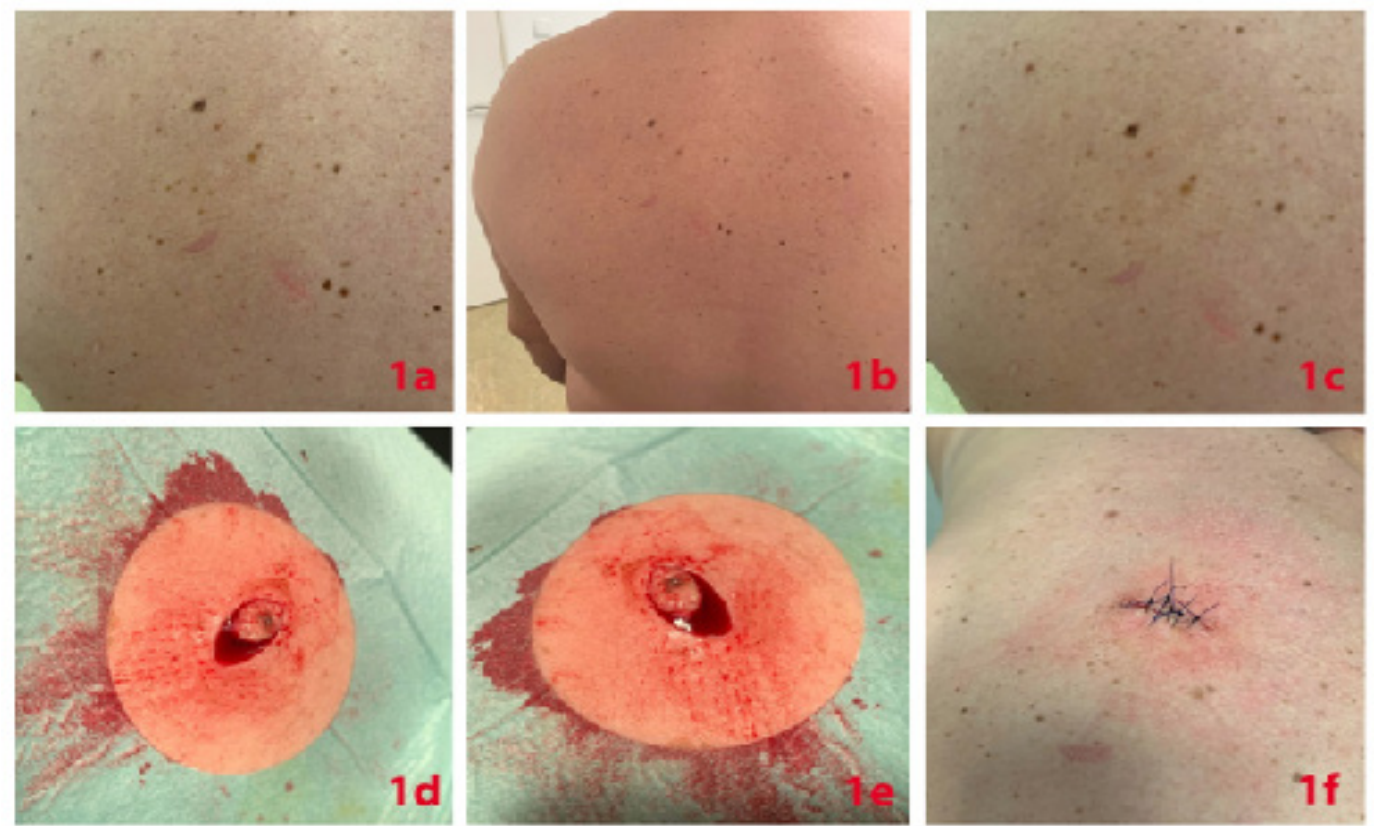

Figures 1a-1c: Multiple acquired melanocytic nevi in the dorsal area, some of which are dysplastic

Figures 1d-1f: Surgical removal of a dysplastic nevus by elliptical excision under local anesthesia and closure of operative defect by of single skin sutures 

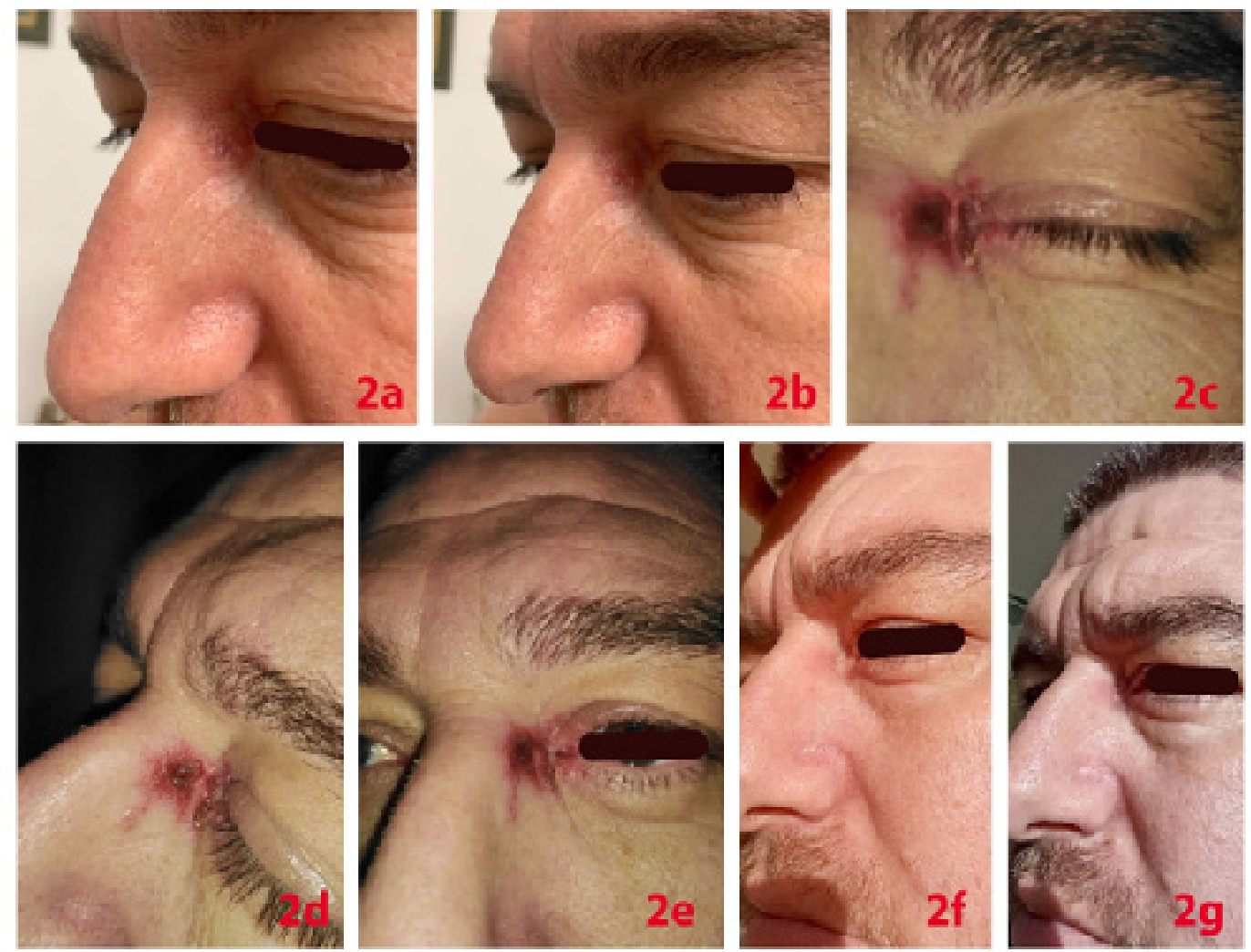

Figures 2a, 2b: High-risk basal cell carcinoma adjacent to the medial corner of the eye on the left. The diagnosis was verified histopathologically by skin biopsy

Figures 2c, 2d, 2e: Clinical picture after treatment with one session of cryoimmunotherapy

Figures 2f, 2g: Clinical picture after 21 days, followed by complete clinical remission

\section{Discussion}

This seemingly trivial case is interesting from 3 main points of view: 1) Innovative treatment of high-risk non-melanocytic skin tumors with a new treatment regimen, 2) drug mediated carcinogenesis - in this case the drug valsartan, which could be considered as a possible pathogenetic trigger for generating melanocytic and non-melanocytic skin tumors and 3) the most important one about the possible role of nitrosamines as triggers of malignant skin tumors.

High-risk basal cell carcinomas are a challenge for dermatologists and often require specialized management using the known standard surgical approaches: elliptical excision, Mohs surgery, and plastic reconstructive surgical techniques, including the various types of rotational or transposition flaps for covering the defects [13-15]. Skin transplantation in the form of fullthickness mesh grafts or split skin mesh grafts also proves to be a good option, the application of which depends on the degree of involvement of underlying tissues, the patient's desire to achieve optimal cosmetic results, and the recommendations of the surgical team [16].

Cryoimmunotherapy is proving to be an effective method to treat basal cell carcinomas, especially superficial variants and those less than $2 \mathrm{~cm}$ in diameter or in hard-to-reach or especially risky areas in terms of a number of anatomical features $[17,18]$. The method is not widespread, but is of proven effectiveness in both superficial and non-superficial basal cell carcinomas and squamous cell carcinomas (in situ) with variable localization $[17,18]$.

The reported schemes for the duration and intensity of cryosessions vary and, given the limitations of hard data, this makes the sharing of individual experiences especially significant and desirable.

Drug-mediated / induced carcinogenesis has been the subject of lively debate since $2015 / 2016 / 2017$ [19-21]. It is within this time interval that research teams first alerted the medical public to the possible role of angiotensin receptor blockers / sartans as inducers or risk factors in the development of melanoma and basal cell carcinoma [19-21]. However, at the time of publication of the 2017 data, it was not known whether or not the respective batches of drugs contained nitrosamines [19-21]. International inspections for this purpose were begun only in 2018 [3]. This is what created the possibility for a kind of "pathogenetic accusation" of the active substance [1]. The creation by control bodies of a time interval within which pharmaceutical companies could self-test or "cleanse themselves" of nitrosamine-contaminated 
batches could also be viewed as a kind of "indirect self-recognition of their pathogenetic role" $[1,7,12]$. So, too, could the creation of "protective regimes" for companies around the world and the parallel blocking of checks for the presence or absence of nitrosamines in certain geographical regions [12]. The first European study on the subject linked the use of sartans with a definite increased risk of developing melanoma - between 44\% and 53\%: both "long-term, low-intensity (OR 1.53; 1.05-2.23) and high-intensity (OR 1.44; 0.563.69) angiotensin receptor blocker use was associated with malignant melanoma" [4].

The aim of another, subsequent international retrospective study, presented formally as an American Academy of Dermatology (AAD) poster in Washington, DC in 2016, was to look again for an association (or risk) between the development of melanoma / basal cell carcinoma and the use of various antihypertensive drugs (figure 3) [5]. The results of this study clearly showed a doubling of the risk of developing melanoma after administration of angiotensin receptor blockers. (OR; 2.21; 95\% confidence interval (CI): 1.45-3.36), (figure 3) [5]. The same study also found an approximately 36\% risk of developing basal cell carcinomas after the use of angiotensin receptor blockers for arterial hypertension: (OR; 1.36; 95\%, CI 1-1.83) (figure 3) [5]. In practice, there are international data on "simultaneous or parallel increased risk" of developing melanocytic and non-melanocytic skin tumors after administration of sartans, and there are clinical reports that fully correspond to those described in our patient (figure1,2) [4,5]. The role of angiotensin receptor blockers / sartans in nevus associated melanomas has also been the subject of discussion and serious observation in the medical literature [7,10]. The available data on the subject are indicative of the possible drug triggering of dysplastic nevi in the direction of melanoma after taking sartans as monotherapy or in combination with hydrochlorothiazide) $[7,10]$.

\begin{abstract}
3167
Associbution of melanums and nonmelanoma skin cancer with anthyper. tenslve drugs: A report from the fevenrch on Advene Drug events and Reports project

Kinberiy Sabk. Department of Dermatolagy. Feinberg 5ehool of Medicine Northwestern University, Chicago, II. Uaited States Sama Majewsldi, Depurtment of Dermatolcgy, Feinbers School of Medicine, Nortirwestern University, Chicazo II., United States; Beatrice Nandooe, MD, PhD, Department of Dermatology Feinterg Schvol of Medictae, Narthwestern Lniversity, Chicago, It, Uniced

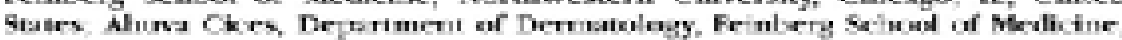
Nonlhwestern tInhersity, Chicaga, IT. Inited States; Denis P. West, PLD Departrnent of Dermatalogy. Feinberg School of Mcdicinc, Northwestern University, Chicaso. 11. United Statess Anne E Lumana. MBChB, Department of Dermatolcgy, Feiabers School of Medicine, Nortinwestern Universaty, Chicazo. II. United States

Introduction: Scme antihypertensive drags may increase the risk of skia eancer, but

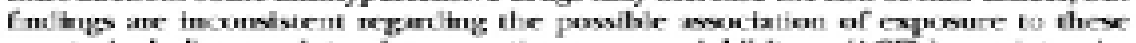
agrents including angisuenvin-comverting enoyne inhihitors (MCFis), angeotensit: receptor blockers (ARIs) and thiscices (T2s) with sccerrence $\alpha \mathcal{Z}$ malignant Exiancena (MM). basal eell carcinoma (BCC) and souamcus exll carciroma (5OC) The aim of this trudy was to investigate further these poezdole ascociations.

Method: The Northwestem Medicine Enterpeise Data Warehouse repostorv was searehed to detect pateats, age 18 \&9 years, with two consecutive peecenptions for an ACF, AFB af IZ Subsequent diagnoses of MM, BCC of SCC oceuming at least 2

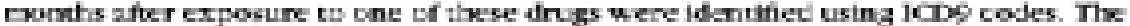

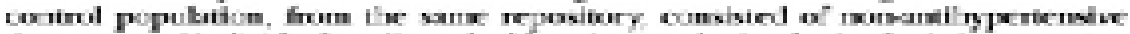

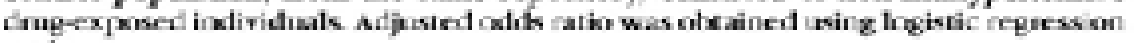
analyses.

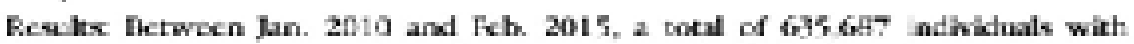

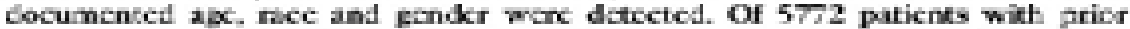
expogure to an ARB: 23 MM. 45 ECC and 13 SCC were detceted. OH 13617 patierts bith priour exposure to an ACE: $28 \mathrm{MM}, 94 \mathrm{BCC}$ and $35 \times \mathrm{CC}$ were detected. Of 3400 pacierns opered to a TZ $9 \mathrm{MM}, 18 \mathrm{kCC}$ amd $13 \mathrm{SOC}$ were detected. After ad usting

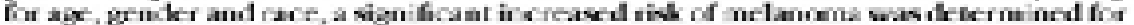

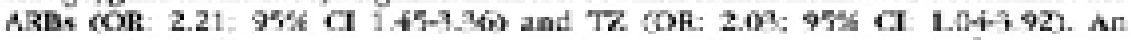

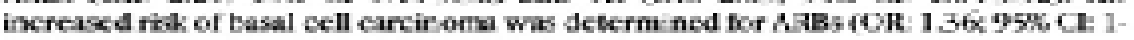

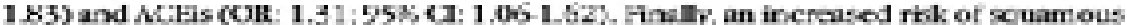

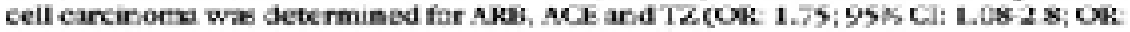

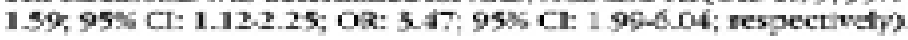

Conctuxicns: These findings serve to delireare the sssociation of malipnant

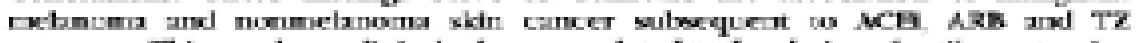

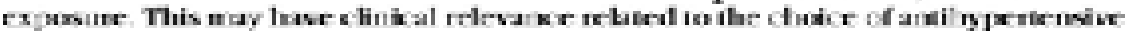
agrent, particulerly for paticnits with known risk factors hor skin cancer. Given the widespincad use of these Aruge, increased pharracovicilance, alocg wixh cducaton For both pasients and heslth practitiocers, are warranted.
\end{abstract}

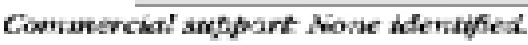

Figure 3: Poster from AAD, Washington DC, 2016 [8]. 
Of interest are the subsequent observations of the same American group of researchers involved with the previously mentioned 2016 AAD poster, who after study of a significantly increased number of patients, found an even stronger association / risk of nonmelanocytic skin tumors after use of angiotensin receptor blockers / sartans (depending on the applied statistics - between 2 to about three times increased risk for BCC: unadjusted OR (95\% CI): 2,16 (1,85-2,52)/ adjusted OR (95\%CI): 2,86 (2,13-3,83) [21], (figure4).

According to the data presented by colleagues, it is clear that in parallel with the risk of BCC, there is a risk of developing melanoma after the use of sartans; this risk is between $24 \%$ and more than $225 \%$ (depending on the used statistical methodology: adjusted / not adjusted) [21] (figure 4).

None of the presented studies comment on or exclude the most important factor for carcinogenesis: the nitrosamine contaminants $[4,5,7,10,21]$. The most serious problem in the group of patients taking angiotensin receptor blockers for the treatment of hypertension is the elucidation of the precise cause, or means by which carcinogenesis is triggered $[1,7]$. A particular problem is the lack of verification of a number of generic and original preparations on the pharmaceutical market as to whether or not they are affected by nitrosamine contamination; as a result, nitrosamines cannot be entirely excluded as generators of melanomas and basal cell carcinomas [1,7]. The available information leads to the conclusion that Nitrosamines are probably responsible for the potentiation of the neoplastic processes of various types of tumors in the human body [1,6].

Gis Ceneer Asecieted vith Expoiure to Aatilyperteakive Drups

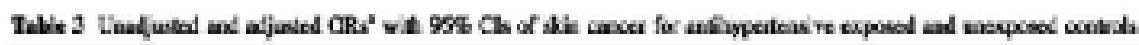

\begin{tabular}{|c|c|c|c|c|}
\hline & Reserence & Eatal sall eareisoas & Squincas cell cascixora & Malignaet melatoes: \\
\hline \multicolumn{5}{|l|}{ ACEs } \\
\hline Exposed, $=(\pi)$ & $27.134[25]$ & $533(1.96)$ & $12[0.67)$ & $187(0.57)$ \\
\hline therpoued, $n[(w)$ & $51,399(75)$ & $T 2(095)$ & $217(027)$ & $282(0.29)$ \\
\hline Unadiuted CR (95\% CD) & 1 & $209\langle 1.87-234)$ & $2.53[207-305)$ & $2.42(2.00-2.95)$ \\
\hline 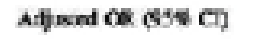 & 1 & $273(1,78-231)$ & $1.2(137-776)$ & $131(0.97-4 x)$ \\
\hline \multicolumn{5}{|l|}{ ARES } \\
\hline Exproval, e $(\boldsymbol{\phi})$ & 19818 (25) & $283(205)$ & I 10.77 & st (n.sin) \\
\hline Unesposed, n (\$) & $41,454(75)$ & $397(096)$ & $128(031)$ & $\ln (0.31)$ \\
\hline Unadjusted CR (95\% CI) & 1 & $2.15(1.85-2.52)$ & $2.50(1.93-3.23)$ & $2.25(1.73-2.24)$ \\
\hline Affund CE (SSE CD & $\mathbf{1}$ & $285(2.13-3.35)$ & $2.22(137-361)$ & $1.36(0.54-3.65)$ \\
\hline \multicolumn{5}{|l|}{ Trianides } \\
\hline Expont, n (W) & $15,166(25)$ & $262(17)$ & $180(086)$ & $59(0.65)$ \\
\hline Unerposed, n[\$] & 45.478 [75] & $457\langle 1.0 \%)$ & $132[0.29)$ & $145(0.32)$ \\
\hline Unadjusted CR (95\% CI) & 1 & $1.73(1,29-2.02)$ & $2.97(2.35-3.79)$ & $2.06(1.59-2.66)$ \\
\hline Adjened C6 (SS\% CD) & 1 & $2.11(1.00-2.79)$ & $4.11(2.66-6.35)$ & $1.82(201-3.52)$ \\
\hline
\end{tabular}

Figures 4: Table regarding the possible risk of developing melanoma and nonmelanoma skin cancer regarding the data from Nardone B et al [9].

\section{Conclusion}

We have presented a rare case of a possible drug-induced high-risk epithelial tumor - basal cell carcinoma - near the eye, occurring in parallel with multiple eruptive, partly dysplastic nevi, following the administration of valsartan. For the first time in the world literature, the possible key role of nitrosamines as inducers of melanoma, melanoma precursors and non-melanocyte skin cancers is discussed. The data analysed in this scientific paper concern drugs that have not been checked as batches by control authorities for the presence or absence of nitrosamines. An innovative, unpublished scheme for the treatment of a nonmelanoma skin tumor by immunocryotherapy has been applied, leading to complete remission.

\section{References}

1. Tchernev G, Bitolska A, Patterson JW. Telmisartan (and/or nitrosamine) - induced occult melanoma: first reported case in world literature. Expert Rev Clin Pharmacol. 2021:1-6.

2. Yuspa SH. Cutaneous chemical carcinogenesis. J Am Acad Dermatol. 1986;15(5 Pt 1):1031-1044.

3. Tchernev G, Temelkova I. Valsartan Induced Melanoma?! First Description in Medical Literature! Open Access Maced J Med Sci. 2018;6(12):2378-2380.

4. Schmidt SA, Schmidt M, Mehnert F, Lemeshow S, Sørensen HT. Use of antihypertensive drugs and risk of skin cancer.J EurAcadDermatolVenereol. 2015;29(8):1545-1554.

5. Sable K, Majewski S, Nardone B, Cices A, West DP, Laumann AE. Association of melanoma and nonmelanoma skin cancer with antihypertensive drugs: A report from the Research on Adverse Drug 
events and Reports project. J Am AcadDermatol 2016;74(5):AB221.

6. Tchernev G, Malev V, Patterson JW, Bitolska A, Batashki A, Cardoso JC, Poterov G, Mangarov, Batashki I. Sartans , Nitrosamines and melanoma development: The hidden truth. J Medical Review (Bulgarian). 2021;57(1):36-37.

7. Tchernev G, Patterson JW. Telmisartan/hydrochlorothiazide-induced nevus-associated cutaneous melanoma: first report in the medical literature. Expert Rev Clin Pharmacol. 2021;19:1-5.

8. Tchernev G, Temelkova I. Irbesartan Induced Cutaneous Melanoma! Second Case in the Medical Literature! Open Access Maced J Med Sci. 2019;7(1):121-123.

9. Tchernev G, Temelkova I. Drug-Induced Melanoma: Irbesartan Induced Cutaneous Melanoma! First Description in the World Literature! Open Access Maced J Med Sci. 2019;7(1):114-116.

10. Tchernev G, Cardoso JC, Poterov G. Sartan means Cancer: Valsartan induced Nevus associated cutaneous melanoma. J Medical Review (Bulgarian) 2020;56(6):59-64.

11. Silva IMS, Assersen KB, Willadsen NN, Jepsen J, Artuc M, Steckelings UM. The role of the renin-angiotensin system in skin physiology and pathophysiology. Exp Dermatol. 2020;29(9):891-901.

12. Tchernev G, Poterov G. Drug Induced Cancers: Simultaneously Development of Cutaneous Melanoma, Colon Carcinoma and Kaposi Sarcoma under Valsartan/ Hydrochlorothiazide.Clin Res Dermatol Open Access. 2020.

13. Puig S, Berrocal A. Management of high-risk and advanced basal cell carcinoma. Clin TranslOncol. 2015;17(7):497-503.

14. Prickett KA, Ramsey ML. Mohs Micrographic Surgery. In: StatPearls. Treasure Island (FL): StatPearls Publishing. 2020.
15. Rao JK, Shende KS. Overview of Local Flaps of the Face for Reconstruction of Cutaneous Malignancies: Single Institutional Experience of Seventy Cases. J CutanAesthet Surg. 2016;9(4):220-225. 16. Kim GW, Bae YC, Bae SH, Nam SB, Lee DM. A clinical review of reconstructive techniques for patients with multiple skin cancers on the face. Arch Craniofac Surg. 2018;19(3):194-199.

17. MacFarlane DF, El Tal AK. Cryoimmunotherapy: superficial basal cell cancer and squamous cell carcinoma in situ treated with liquid nitrogen followed by imiquimod. Arch Dermatol. 2011;147(11):13261327.

18. Gaitanis G, Bassukas ID. Immunocryosurgery for non-superficial basal cell carcinoma: a prospective, open-label phase III study for tumours $\leq 2 \mathrm{~cm}$ in diameter. Acta Derm Venereol. 2014;94(1):38-44.

19. Schmidt SA, Schmidt M, Mehnert F, Lemeshow S, Sørensen HT. Use of antihypertensive drugs and risk of skin cancer.J EurAcadDermatolVenereol. 2015;29(8):1545-1554.

20. Sable K, Majewski S, Nardone B, Cices A, West DP, Laumann AE. Association of melanoma and nonmelanoma skin cancer with antihypertensive drugs: A report from the Research on Adverse Drug events and Reports project. J Am AcadDermatol. 2016;74(5):AB221.

21. Nardone B, Majewski S, Kim AS, Kiguradze T, Martinez-Escala EM, Friedland R, Amin A, Laumann AE, Edwards BJ, Rademaker AW, Martini MC, West DP. Melanoma and Non-Melanoma Skin Cancer Associated with Angiotensin-Converting-Enzyme Inhibitors, AngiotensinReceptor Blockers and Thiazides: A Matched Cohort Study. Drug Saf. 2017;40(3):249-255. 